\title{
RESULTS OF DRILLING OSTEOCHONDRITIS DISSECANS BEFORE SKELETAL MATURITY
}

\author{
J. BRADLEY, D. J. DANDY
}

From the Newmarket General Hospital, Suffolk

\begin{abstract}
We report the arthroscopic drilling of classical lesions of osteochondritis dissecans in 11 knees in 10 children with at least six months history and no sign of clinical or radiological improvement. There were eight boys and two girls and the average age at operation was 12 years 11 months. Relief of pain was noticed within days of operation; radiological healing occurred within 12 months in nine of the 11 knees.
\end{abstract}

Much has been written about osteochondritis dissecans since it was first described by Paget in 1870, but its cause and treatment remain controversial. Reports on its natural history are sometimes confused by the inclusion of patients with epiphyseal dysplasia (Caffey et al 1958) and acute osteochondral fractures (Aichroth 1971, 1977), but the patients we have studied all had 'classical' osteochondritis dissecans of the type described by König (1887), Green and Banks (1953) and Linden (1976). The condition is the same as Smillie's (1980) juvenile osteochondritis dissecans.

Conservative treatment (Edelstein 1954), drilling (Clanton and DeLee 1982) and cast immobilisation (Smillie 1957) have all been tried with varying degrees of success. Some lesions resolve spontaneously (Edelstein 1954; Löfgren 1954), but others lead to the formation of a loose body and a defect in the femoral condyle.

We now report the outcome of drilling to treat persistent symptoms in young patients before epiphyseal closure.

\section{PATIENTS AND METHODS}

Presenting symptoms. No patient had a history of definite trauma, a family history of osteochondritis dissecans, or generalised ligamentous laxity. Apart from one patient who had both knees affected, none had any other joint disorder.

J. Bradley, FRCS, Senior Orthopaedic Registrar

D. J. Dandy, FRCS, Consultant Orthopaedic Surgeon

Department of Orthopaedic Surgery, Newmarket General Hospital, Newmarket, Suffolk CB8 7JG, England.

Correspondence should be sent to $\mathrm{Mr} \mathrm{D}$. J. Dandy at The Old Vicarage, Great Wilbraham, Cambridge CBI 5JF, England.

(C) 1989 British Editorial Society of Bone and Joint Surgery $0301-620 \mathrm{X} / 89 / 4152 \$ 2.00$

J Bone Joint Surg [Br] 1989:71-B :642-4.
Indications. Operation was advised for persistent pain lasting over six months without clinical improvement or radiological signs of healing. Ten patients with 11 affected knees met these criteria over an 11-year period during which 5000 arthroscopies were performed for non-urgent conditions. The mean age at onset of symptoms was 11 years 6 months ( 9 years 11 months to 12 years 7 months) and the mean age at operation was 12 years 11 months (11 years 7 months to 13 years 7 months). There were eight boys and two girls (one with bilateral problems) with six right and five left knees involved.

Site. All the lesions were found on the medial femoral condyle at the 'classical' site of osteochondritis dissecans.

No lesion with similar radiological or arthroscopic appearances was encountered elsewhere on the femoral condyles during the period of study.

Technique of operation. The knees were examined arthroscopically under general anaesthesia with a tourniquet inflated, but without exsanguination. The lesions were localised by identifying the ring of soft articular cartilage around the margin of the fragment with a probing hook. A minimum of six holes were then made through the articular cartilage into the fragment and the underlying epiphysis using a $1.5 \mathrm{~mm}$ Kirschner wire. A 'jump' could usually be felt as the wire passed from the fragment of bone across the gap into the main body of the epiphysis. The holes were made with hand instruments; power tools were not used. The operations were all performed by one surgeon (DJD). Full weight-bearing was allowed without splintage on the day after operation with an immediate return to everyday activities. Sport was not permitted for a minimum of two months.

Review. Patients were reviewed and radiographed at a minimum of 12 months after operation (mean 2 years 8 months, range 1 to 5 years). It would have been instructive to re-arthroscope all knees at 12 months after operation, but this could not be justified in the absence of symptoms 




Fig. 1a

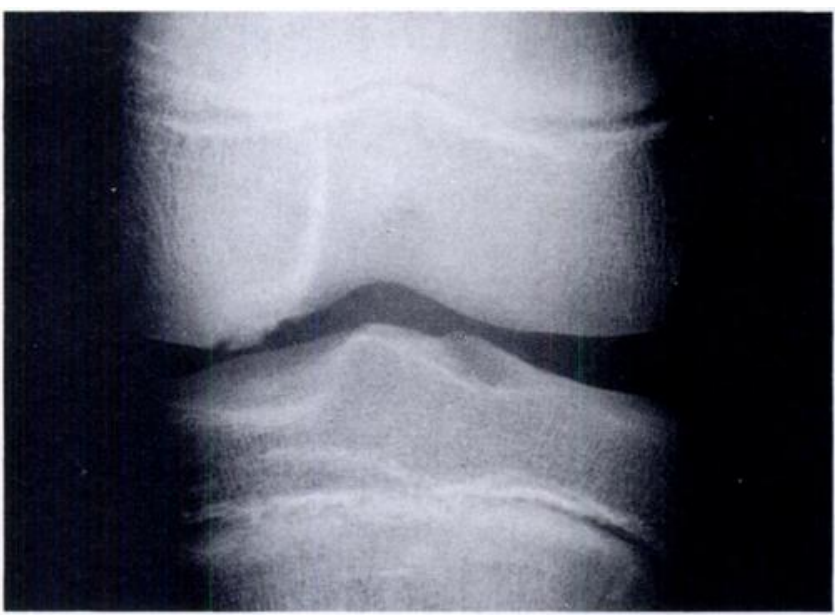

Fig. 1c

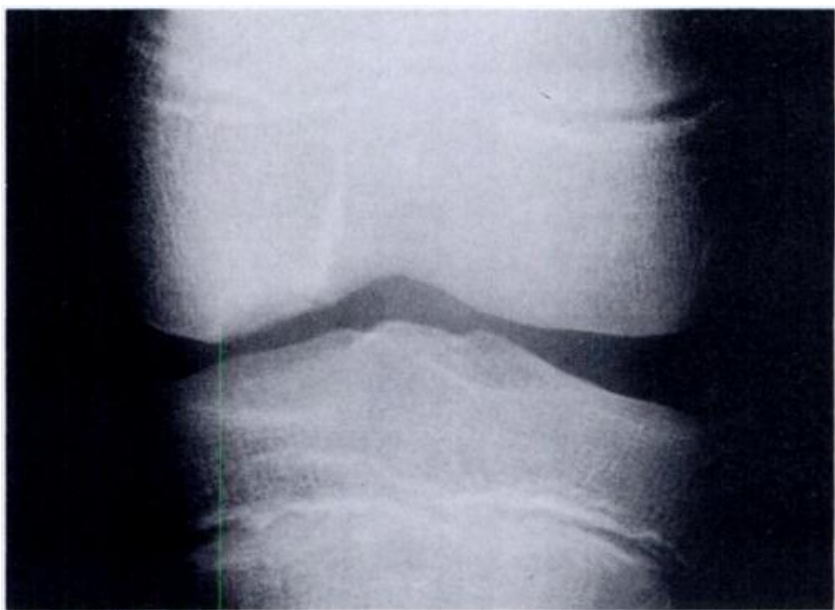

Fig. 1b

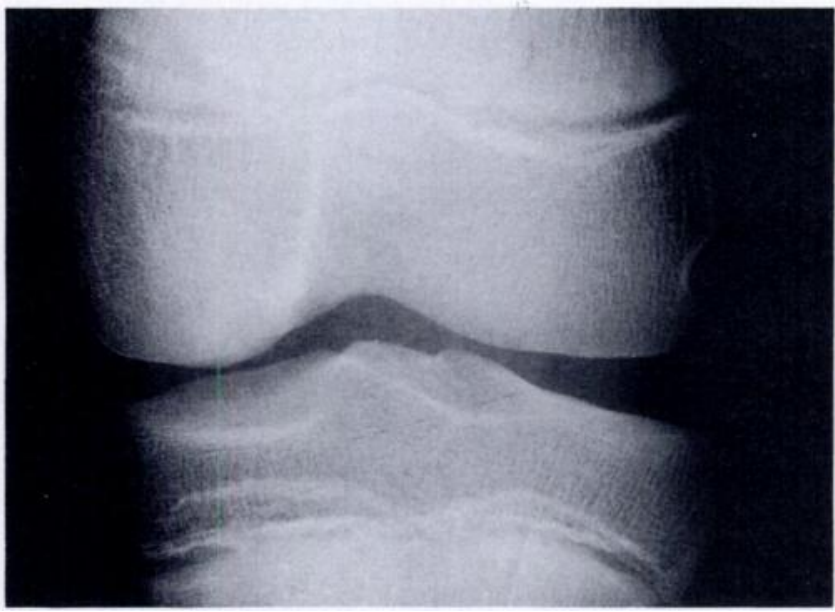

Fig. 1d

Radiographs of the left knee of a 13-year-old boy: a) one year after presenting with pain in the knee; b) two months after arthroscopic drilling of the osteochondritic lesion; c) four months later the fragment has united to the condyle and there are signs of healing; d) two years after drilling healing is complete.

or radiographic abnormality. One patient did require arthroscopy for the investigation of subsequent anterior knee pain.

\section{RESULTS}

The pain for which the operation was done often disappeared within one week of operation. Twelve months after operation, nine of the 11 knees remained free of pain and the remaining two patients had less pain, but symptoms had not resolved completely. At 12 months all knees had a full range of normal movement. One knee, which eventually showed loose body formation, had occasional effusions.

Radiology. Nine of the 11 knees showed union of the isolated fragment with the rest of the lower femoral epiphysis within 12 months of operation (Fig. 1). One lesion, as mentioned above, did not unite; the subsequent loose body was removed arthroscopically five years later.
One other lesion took two years to unite during which time mild symptoms persisted. Five years after drilling, this knee was examined arthroscopically for anterior knee pain when the patient was 17 years of age. The drill holes were visible as depressions in the articular surface; some showed slight fibrillation at the site of entry of the Kirschner wire. The cartilage overlying the lesion was intact but softer than normal. No area of demarcation was palpable around the lesion.

\section{DISCUSSION}

Although the cause of osteochondritis dissecans is not known, it is agreed that part of the epiphysis develops separately from the main bony mass. This separated area grows at the same rate as the rest of the condyle and reunites with the epiphysis without treatment in some patients. The aim of our treatment was to unite the fragment with the epiphysis and eliminate the translucent 
line between the two in those patients in whom natural union did not occur. We found that drilling through the fragment into the epiphysis was followed by restoration of a normal radiographic appearance in 10 of the 11 knees.

The holes were made from within the joint through intact articular cartilage into the femur, rather than from 'outside in' through a second incision, in order to prevent loosening of the fragment. This avoided an additional incision and made it easier to place the holes accurately, but it left a permanent lesion on the articular surface. There is no evidence that these drill holes, which are not in a weight-bearing area, are followed by degenerative change. Internal fixation was not used; it is possible that when fragments are fixed internally with a pin or screw, the effective part of the operation may be the hole and not the fixation. Because the lesions had not been made unstable we saw no need to restrict loading; immediate weight-bearing was allowed without immobilisation.

A surprising finding was the rapid relief of pain after drilling, which suggests that the pain may have been due to increased pressure at the line of separation between the fragment and the epiphysis.

Our results apply only to true osteochondritis dissecans before skeletal maturity. During the period of study two adults were seen with intact cartilage overlying classical lesions of osteochondritis dissecans. Both lesions were drilled but neither patient was relieved of pain and there was no radiological union. However, before skeletal maturity, percutaneous drilling under arthroscopic control is an effective treatment for true osteochondritis dissecans.

No benefits in any form have been received or will be received from a commercial party related directly or indirectly to the subject of this article.

\section{REFERENCES}

Aichroth P. Osteochondritis dissecans of the knee: a clinical survey. $J$ Bone Joint Surg [ Br] 1971 ; $53-\mathrm{B}: 440-7$.

Aichroth PM. Osteochondral fractures and osteochondritis dissecans in sportsmen's knee injuries. J Bone Joint Surg [ Br] 1977;59-B:108.

Caffey J, Madell SH, Royer C, Morales P. Ossification of the distal femoral epiphysis. J Bone Joint Surg [ Am] 1958:40-A :647-54.

Clanton TO, DeLee JC. Osteochondritis dissecans : history, pathophysiology and current treatment concepts. Clin Orthop 1982;167: 50-64.

Edelstein JM. Osteochondritis dissecans with spontaneous resolution. J Bone Joint Surg [Br] 1954;36-B:343.

Green WT, Banks HH. Osteochondritis dissecans in children. $J$ Bone Joint Surg [Am] 1953:35-A :26-47.

König F. Ueber freie Körper in den Gelenken. Dtsch Z Klin Chir 18878:27:90-109.

Lindén B. The incidence of osteochondritis dissecans in the condyles of the femur. Acta Orthop Scand 1976:47:664-7.

Löfgren L. Spontaneous healing of osteochondritis dissecans in children and adolescents: case of multiple ossification centres in distal epiphysis of humerus and rare "OS epicondyli medialis humeri". Acta Chir Scand 1954:106:460-78.

Paget J. On the production of some of the loose bodies in joints. St Bartholomen's Hosp Reports 1870;6:1-4.

Smillie IS. Treatment of osteochondritis dissecans. J Bone Joint Surg $[\mathrm{Br}]$ 1957;39-B:248-60.

Smillie IS. Diseases of the knee joint. 2nd ed. Edinburgh etc: Churchill Livingstone, 1980. 